\title{
Paradigm change in hydrogel sensor manufacturing: from recipe-driven to specification-driven process optimization
}

\author{
M. Windisch ${ }^{1}$, K.-J. Eichhorn ${ }^{2}$, J. Lienig ${ }^{1}$, G. Gerlach ${ }^{3}$, and L. Schulze ${ }^{1}$ \\ ${ }^{1}$ Institute of Electromechanical and Electronic Design, Dresden University of Technology, \\ 01062 Dresden, Germany \\ ${ }^{2}$ Leibniz Institute of Polymer Research Dresden, Hohe Str. 6, 01069 Dresden, Germany \\ ${ }^{3}$ Solid-State Electronics Laboratory, Dresden University of Technology, 01062 Dresden, Germany
}

Correspondence to: M. Windisch (markus.windisch@tu-dresden.de)

Received: 15 October 2015 - Revised: 18 January 2016 - Accepted: 22 January 2016 - Published: 10 February 2016

\begin{abstract}
The volume production of industrial hydrogel sensors lacks a quality-assuring manufacturing technique for thin polymer films with reproducible properties. Overcoming this problem requires a paradigm change from the current recipe-driven manufacturing process to a specification-driven one. This requires techniques to measure quality-determining hydrogel film properties as well as tools and methods for the control and optimization of the manufacturing process. In this paper we present an approach that comprehensively addresses these issues. The influence of process parameters on the hydrogel film properties and the resulting sensor characteristics have been assessed by means of batch manufacturing tests and the application of several measurement techniques. Based on these investigations, we present novel methods and a tool for the optimization of the cross-linking process step, with the latter being crucial for the sensor sensitivity. Our approach is applicable to various sensor designs with different hydrogels. It has been successfully tested with a sensor solution for surface technology based on PVA/PAA hydrogel as sensing layer and a piezoelectric thickness shear resonator as transducer. Finally, unresolved issues regarding the measurement of hydrogel film parameters are outlined for future research.
\end{abstract}

\section{Introduction}

Stimuli-sensitive hydrogels are swellable polymer networks. They respond to changes in the $\mathrm{pH}$ value and the concentration of certain kinds of ions or organics, respectively, with well-defined, reversible shifts of their swelling degree. This chemo-mechanical transducer effect together with the wide diversity of available polymers qualifies them as versatile sensing layers for a multiplicity of measurement tasks (Tokarev and Minko, 2009). However, despite more than 1000 scientific publications in the last decade and numerous promising designs (Bashir et al., 2002; Richter et al., 2004; Trinh et al., 2006), hydrogel sensors have still not reached the commercial mass product level. One reason for that is the lack of a well-studied, controllable and scalable manufacturing process for thin hydrogel layers in the lower micrometre or sub-micrometre range. Such thin films are necessary in order to meet the requirement of industrial sensing applications for response times of less than a minute.

This lack of knowledge can be vividly illustrated by comparing the design and manufacturing of hydrogel sensors with that of traditional mechanical sensors. The outcome of the design process of mechanical systems is usually a set of physically defined and measureable parameters with certain tolerances for each part. Typical examples are length specifications, standardized fits or values for the surface roughness. Furthermore, the design and the manufacturing technique need to be matched. Injection moulding, for example, imposes certain restrictions on the design of the part geometry. Conversely, design specifications, like very narrow tolerance ranges, may require certain manufacturing techniques (e.g. honing). This specification-driven procedure ensures 
the interchangeability of parts or manufacturers as well as the functionality of the product. Function-based declarations ("Part A needs to fit in part B with a friction force of $10 \mathrm{~N}$. .) and recipes ("Polish with 400 grit sandpaper for $10 \mathrm{~min}$ ") are usually avoided.

The current state of the design and manufacturing of thinfilm hydrogel sensors contradicts these principles. Specifications are often function-based, such as "The hydrogel should have a sufficient swelling degree." This is due to a lack of proven measurement techniques for the quality-determining physical parameters and, as a result of this, a knowledge gap regarding the optimal values and acceptable tolerance ranges of these parameters. The manufacturing is mostly recipedriven ("Spin-coating at $3000 \mathrm{rpm}$ for 3 min."), because the precise quantitative interrelations between the controllable process parameters and the resulting values of the qualitydetermining film parameters are in most cases unknown.

It was our objective to address these shortcomings by performing the first process-oriented study of the manufacturing of thin hydrogel layers using the example of a sensor solution for monitoring the concentration of industrial cleaners (main component: sodium pyrophosphate) in surface technology. The outcome, presented in this paper, contributes to the following research questions, affecting a wide range of hydrogel sensors for industrial, biomedical and other applications.

- What is a suitable versatile manufacturing process for thin hydrogel films?

- Which measurement techniques are feasible for the monitoring of quality-determining film parameters?

- Which process parameters are crucial for the quality of the manufactured sensors and which methods exist for their sensor-specific optimization?

\section{Initial hydrogel sensor solution}

This paper is structured in three main sections, according to these issues.

\subsection{Sensor principle and motivation}

The sensor, previously presented in Windisch and Junghans (2013), consists of a piezoelectric thickness shear resonator (TSR, AT-cut quartz crystal) as a highly sensitive transducer with a PVA/PAA (polyvinyl alcohol/polyacrylic acid) hydrogel coating as a sensing layer. These two coupled elements form an electro-mechanical vibration system. It shifts its frequency-dependent impedance if the hydrogel changes its swelling degree together with its mass and complex shear modulus. The sensor is excited with an AC voltage in a frequency range of $\pm 20 \mathrm{kHz}$ around the resonance frequency (about $10 \mathrm{MHz}$ ) and the corresponding current is measured. The subsequent pre-processing calculates

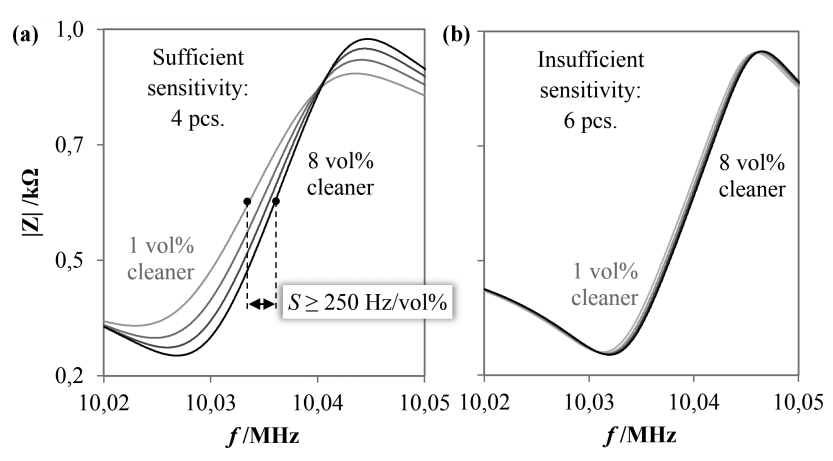

Figure 1. Variance of sensor sensitivity in the sample batch of 10 PVA/PAA-coated TSRs: (a) four sensors have a sufficient sensitivity, and (b) six sensors have an insufficient sensitivity.

the electrical impedance and converts it to the frequency domain. Figure 1 shows examples of the resulting impedance spectra, from whose changes the measured concentration is finally computed through further data processing steps (see Windisch and Junghans, 2014, for details).

The impedance spectrum of a TSR with a thin viscoelastic hydrogel film depends on four parameters (Bruenig, 2011):

- thickness $d$,

- density $\rho$,

- storage modulus $G^{\prime}$, and

- loss modulus $G^{\prime \prime}$.

The density of a swollen hydrogel varies at the utmost between $1 \mathrm{~g} \mathrm{~cm}^{-3}$ (water) and $1.3 \mathrm{~g} \mathrm{~cm}^{-3}$ (dry polymer) and can therefore be regarded as nearly constant for a given swelling degree. The thickness $d$ and the complex shear modus $G^{*}=G^{\prime}+i G^{\prime \prime}$ strongly depend on the manufacturing process. They must be kept within narrow tolerance ranges in order to assure an optimal and reproducible sensor function.

The quality criterion for the sensor is its sensitivity, which is defined as the concentration-dependent frequency shift of the inflection point of the impedance spectra $S=$ $\partial f_{\text {ip }} / \partial c$ (Fig. 1a). Other deviations, such as offsets of the frequency or the impedance, can be corrected with appropriate measurement-processing algorithms and calibration procedures (Windisch and Junghans, 2014). However, an insufficient sensitivity derogates the signal-to-noise ratio and, consequently, directly limits the achievable measurement accuracy.

A sample batch with a volume of ten pieces was produced and characterized in order to investigate the manufacturability of the previously developed sensor. Figure 1 shows examples of the different sensor characteristics that occurred. The selected application requires a sensitivity of at least $250 \mathrm{~Hz} \mathrm{vol} \%^{-1}$ in order to achieve the necessary measurement accuracy for the cleaner concentration. Using this criterion, the yield of the batch was $40 \%$, which corresponds 
to our experiences from previous manufacturing tests. This low yield more than doubles the effective sensor cost, which puts them out of economical range for many industrial applications, for example in surface technology.

Hence, it is necessary to study the interrelation between process parameters and the function determining hydrogel film properties in order to optimize the manufacturing technique and improve the yield. Furthermore, research and, subsequently, volume production require suitable measurement techniques for these parameters.

\subsection{Manufacturing process for thin hydrogel layers}

Spin-coating was chosen as a process step for creating thin hydrogel layers on substrates. It produces homogenous films with a controllable thickness and can be performed on costsaving standard equipment. In exchange for these advantages, it also imposes three restrictions for the overall process and the hydrogel synthesis.

- All hydrogel components must be soluble in the same solvent.

- The viscosity of the solution must be well defined and constant (for a given shear rate $s$ ).

- The cross-linking has to take place in dry polymer, since the solvent must vaporize during the spin-coating in order to obtain uniform and stable films.

One consequence of these restrictions is that chemical cross-linking in liquid or semi-liquid state is not compatible with spin-coating. Even long gelation times of up to $40 \mathrm{~min}$ lead to a constant drift of the solution viscosity, which prevents the batch coating of films with a constant and reproducible thickness.

The low molecular mobility in dry polymers severely limits the cross-linking rate and may even prevent a sufficient network formation. Some publications show that radiationchemical cross-linking is in principle feasible for dry films (Buller et al., 2013; Hegewald et al., 2005). However, these methods impose additional technological restrictions or specific requirements, like the co-polymerization of special cross-linker molecules. This is contrary to the goal of a simple and inexpensive manufacturing technology.

Another approach is to apply a cross-linking temperature above the glass transition temperature $T_{\mathrm{G}}$, where the molecular mobility is significantly increased. The thermal crosslinking of PVA and PAA starts at about $120^{\circ} \mathrm{C}$ (Arndt et al., 1999 ). Both polymers are in a liquid-like rubbery state at this temperature and provide a sufficient chain mobility for the cross-linking reaction. PVA and PAA are thermally crosslinked for these reasons and the simplicity of this method.

Based on these preliminary considerations, the following manufacturing process was used for the subsequent studies.

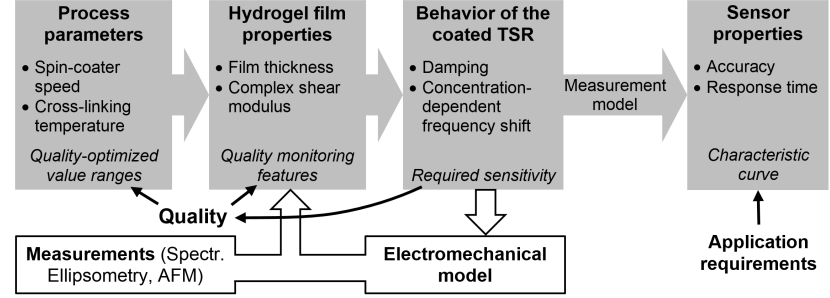

Figure 2. Methodology of the manufacturing process with a comprehensive optimization approach.

1. Deposition of mercaptoundecanoic acid from a $1 \mathrm{mM}$ ethanol solution as an adhesion promoter between the gold electrode of the TSR and the hydrogel.

2. Polymer film formation through spin-coating (see Table A1 for speed profile) of an aqueous solution of PVA (PolySciences, MW $\approx 125000 \mathrm{~kg}$, $88 \mathrm{~mol} \%$ hydrol., $T_{\mathrm{G}}=85^{\circ} \mathrm{C}$ ) and PAA (PolySciences, $\mathrm{MW} \approx 450000 \mathrm{~kg}, T_{\mathrm{G}}=106^{\circ} \mathrm{C}$ ) in the ratio $8: 1$.

3. Thermal cross-linking of the two polymers through the formation of anhydrides and ester bonds using the hydroxyl groups and the carboxylic acid groups (Arndt et al., 1999).

The thickness $d$ and homogeneity $s^{2}(d)$ of the hydrogel film are predefined through both the interrelation of the polymer solution concentration and the spin-coating speed. In the subsequent thermal cross-linking step, the temperature profile determines the complex shear modulus $G^{*}$ and the range of its concentration-dependent changes. This allows the separate optimization for both parameters without disturbing interrelations.

Figure 2 shows the process-oriented approach for the application-specific sensor optimization. The goal is defined by the application, which requires certain sensor properties in order to fulfil the measurement task. The measurement model matches the characteristic curve to the requirements, provided that the coated TSR has a sufficient sensitivity.

Considering these interdependencies, the ultimate goal of the process optimization is to find the value ranges of the process parameters that ensure the desired film properties and, consequently, a sufficient sensitivity. In a first step, this requires a detailed understanding of both the interrelations between the hydrogel film properties and the resulting behaviour of the coated TSR. From this, target values for $d, G^{\prime}$ and $G^{\prime \prime}$ can be defined and used as quality monitoring features. The second step is then an experimental investigation of the interrelation between the process parameters and these monitoring features. This concept for the process optimization requires measurement techniques for the thickness and the mechanical properties of thin hydrogel films. 


\section{Measurement techniques for hydrogel film properties}

The relevant hydrogel film properties can be measured using either direct or indirect procedures. We have investigated both approaches for parameters $d$ and $G^{\prime}$. The loss modulus $G^{\prime \prime}$ of films in the sub-micrometre range is difficult to measure. Only the tested indirect model-based measurements (see Sect. 3.2) provide values for $G^{\prime \prime}$ (or the viscosity $\eta$ ) of the hydrogel. The lack of a second, independent measurement technique for the verification of these values prevents a profound evaluation of their accuracy. Furthermore, the qualitative and quantitative interrelations between the process parameters and the loss modulus are still widely unknown. Therefore, the measurement of $G^{\prime \prime}$ is not covered in this paper and will be subject to future research.

\subsection{Direct measurements}

Direct measurements are the first option for investigating the properties of thin hydrogel films. Amongst various tested techniques for measuring the thickness of dry and swollen hydrogel films (see Table A2), spectroscopic ellipsometry and atomic force microscopy (AFM) provided the best results.

Ellipsometry as a measurement principle is based on an optical model, which computes the film thickness from the measured amplitude component $\Psi$ and the phase difference $\Delta$ of light reflected by the sample. By reason of operating completely in the optical domain and providing the thickness as a well-defined output parameter, it is regarded as a direct method in the context of this paper, although ellipsometry is - in a narrower sense - an indirect measurement method.

A variable angle spectroscopic ellipsometer (M-2000 by J. A. Woollam Co.) was used for measuring the average optical thickness $\bar{d}$ and refractive index $n$ of hydrogel layers on TSRs simultaneously. The latter parameter provides additional information on the optical properties, which is useful for evaluating the chemical homogeneity and, to some extent, the material density of the hydrogel (Bittrich et al., 2014; Ogieglo et al., 2015).

AFM was used for measuring Young's modulus $E$ and the storage modulus $G^{\prime}$ (using the relation $E=3 G^{\prime}$ for $v=0.5$ ) of a hydrogel film (Domke and Radmacher, 1998; Markert et al., 2013). However, the effective glass transition temperature of polymers, and therefore $G^{\prime}$, strongly depends on the measurement frequency (Williams et al., 1955). Consequently, the measured effective values of $G^{\prime}$ differ, since the cantilever frequency of an AFM is usually in the range of $10^{1}-10^{2} \mathrm{kHz}$, while the TSR works at $10 \mathrm{MHz}$. A conversion is currently not possible, because the necessary interrelations are still unknown for the specific PVA/PAA hydrogel. Therefore, the directly measured material properties can currently only be used for relative comparisons.

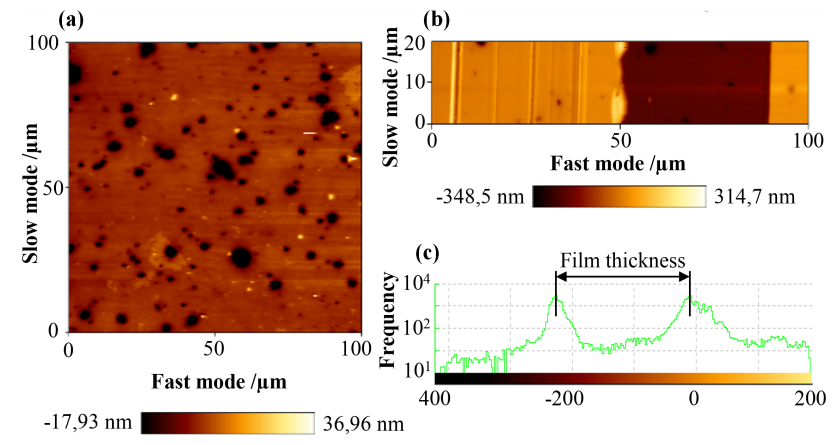

Figure 3. AFM image of (a) the hydrogel surface and (b) a scratch for the determination of the layer thickness with (c) the corresponding height histogram.

In addition to the elastic moduli, AFM can simultaneously measure the thickness of a hydrogel film. Such measurements require a sharp step between the substrate and the film surface, which is generated by scratching the hydrogel film. Figure $3 \mathrm{~b}$ and $\mathrm{c}$ show an image of such a scratch and the corresponding height histogram, respectively. The two peaks in the histogram indicate the most often occurring height values. They represent the hydrogel surface and the TSR surface (scratch), respectively. Hence, the height difference between both is the thickness of the hydrogel layer. This direct measurement procedure allows the determination of the mechanical film thickness at a single position $d(x, y)$.

Gesang et al. (1995) have shown that for polymer films thicker than $10 \mathrm{~nm}$, ellipsometrically measured thickness values $d_{\text {ellips }}$ are significantly larger than the corresponding values $d_{\text {mech }}$ obtained by AFM measurements. With respect to the mechanical (acoustic) transducer principle, $d_{\text {mech }}$ seems more suitable as a quality-determining film parameter than $d_{\text {ellips. }}$. However, the AFM measurements are destructive (scratch is necessary) and very limited in the lateral range. Therefore, they are not feasible for the quality monitoring of the manufacturing process. For this reason, only variable angle spectroscopic ellipsometry (VASE) was used for measuring the film thickness in the subsequent experimental section.

\subsection{Indirect measurements}

Two different approaches were tested for the indirect measurements. The first one is based on the relation between the swelling degree and the storage modulus, given by Eq. (1) (Arndt et al., 2009; Philippova and Khokhlov, 2012).

$G^{\prime}=k_{\mathrm{B}} T \iota\left(\frac{V}{V_{\text {dry }}}\right)^{-\frac{1}{3}}$,

where $k_{\mathrm{B}}$ denotes the Boltzmann constant.

Since the thin hydrogel film is confined in the $x$ and $y$ directions by the TSR, it can only swell in the $z$ direction (thickness $d$ ). Therefore, $G^{\prime}$ depends only on the cross- 
linking density $\iota$ and the measured thickness $d$ (the temperature $T$ was kept constant at $22^{\circ} \mathrm{C}$ ):

$G^{\prime}=k_{\mathrm{B}} T \iota\left(\frac{x_{\text {dry }} y_{\text {dry }} d}{x_{\text {dry }} y_{\text {dry }} d_{\text {dry }}}\right)^{-\frac{1}{3}}=k_{\mathrm{B}} T \iota\left(\frac{d}{d_{\text {dry }}}\right)^{-\frac{1}{3}}$.

The values $d_{\text {ellips }}$ and $G_{\mathrm{AFM}}^{\prime}$, measured in 1 vol $\%$ cleaner concentration, were used for eliminating the unknown value of $\iota$ from the equation. This yields the storage modulus at 8 vol\%:

$G_{\mathrm{cal}}^{\prime}=G_{\mathrm{AFM}, 1 \_\mathrm{vol} \%}^{\prime}\left(\frac{d_{\text {ellips, 8_vol } \%}}{d_{\text {ellips, 1_vol } \%}}\right)^{-\frac{1}{3}}$.

A second option for indirectly measuring the hydrogel film properties is the exploitation of the coated TSR itself as a quartz crystal microbalance (QCM). In this approach, an analytical electromechanical model of the quartz crystal and the attached visco-elastic layer is used for simulating its behaviour in the frequency domain. By matching the simulated spectra to the measured ones, the corresponding values for thickness and the mechanical properties of the hydrogel layer can be extracted from the model. The following explanations provide an overview of the application of this complex method. An in-depth description of the complete procedure is provided by Bruenig (2011).

The basis of the model-based approach is the 1-D solution of the wave differential equation for loaded TSRs (Weihnacht et al., 2007):

$$
Z=\frac{i \zeta C_{0} 2 v_{\mathrm{q}} / d}{1-K^{2} \frac{\tan (\zeta) / \zeta}{1+\frac{i Z_{l}}{2 Z_{\mathrm{q}}} \tan (\zeta) /\left(1-\frac{i Z_{l}}{2 Z_{\mathrm{q}} \tan (\zeta)}\right)}}+i \omega C_{\mathrm{s}} .
$$

In this equation $\zeta$ denotes the normalized frequency $\zeta=$ $\omega d_{\mathrm{q}} /\left(2 v_{\mathrm{q}}\right)$ with the angular frequency $\omega$, the shear wave velocity $v_{\mathrm{q}}$ and the thickness $d_{\mathrm{q}}$ of the quartz crystal. $C_{\mathrm{p}}$ is the ideal electrical capacitance of the plate capacitor formed by the resonating area of the TSR electrodes and $C_{\mathrm{s}}$ is its stray capacitance. $K$ and $Z_{\mathrm{q}}$ are the piezoelectric coupling factor and the acoustic impedance of the quartz crystal, respectively. All of the aforementioned parameters (except for $\omega$ ) are transducer-specific constants for a given TSR. $Z_{1}$ is the load impedance representing the varying mechanical properties of the hydrogel and the surrounding liquid. The latter were modelled as a viscoelastic layer (hydrogel) and a Newtonian half space (water). The Kelvin-Voigt model was used as a simplified representation of the mechanical hydrogel properties. This simplification is necessary, because more sophisticated modelling approaches for hydrogels, like e.g. Burger's model (Gerlach et al., 2005), contain too many free parameters for a unique solution of the equation system. The application of Mason's transmission line model (Bruenig, 2011; Mason, 1950) yields for the described load case

$$
Z_{1}=\frac{i \tan \left(\omega d_{\operatorname{sim}} \sqrt{\frac{\rho}{G^{*}}}\right) \sqrt{\rho G^{*}}+\sqrt{\rho_{w} \cdot i \omega \eta_{w}}}{1+\frac{i \tan \left(\omega d_{\operatorname{sim}} \sqrt{\frac{\rho}{G^{*}}}\right) \sqrt{\rho_{w} \cdot i \omega \eta_{w}}}{\sqrt{\rho G^{*}}}},
$$
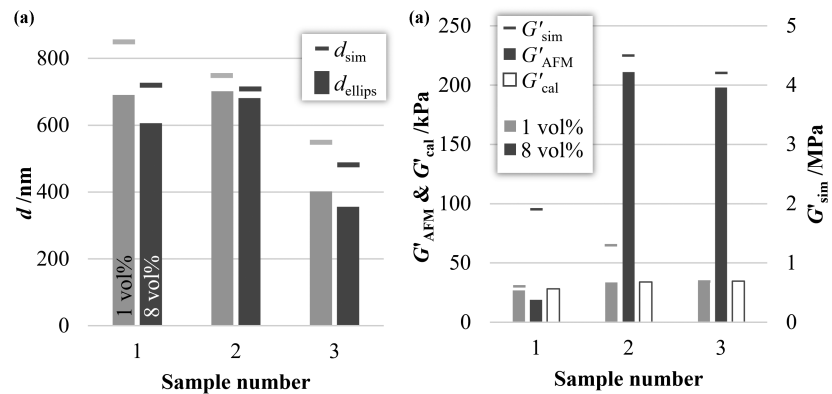

Figure 4. Comparison of directly (measured) and indirectly (simulated, calculated) determined film parameters in 1 and 8 vol\% cleaner concentration: (a) thickness; (b) storage modulus.

with $G^{*}=G^{\prime}+i \omega \eta$ for the hydrogel and the index ${ }_{w}$ denoting the properties of the surrounding liquid half space.

The model-based indirect measurement approach was evaluated in comparison to the direct measurement of the thickness (using VASE) and the storage modulus (using AFM) of three PVA/PAA-coated TSRs in two different cleaner concentrations. Adapted proprietary software (provided by Bruenig, 2011) was used for the numerical simulation of the model and its matching to measured spectra.

\subsection{Results}

Figure 4 illustrates the main outcome of the experimental investigation of the different measurement techniques. The complete results are summarized in Table A3.

All ellipsometrically measured values $\left(d_{\text {ellips }}\right)$ are systematically smaller than the indirectly measured ones $\left(d_{\text {sim }}\right)$. A possible explanation of this effect could be the little pores, which had been found with an AFM scan of the surface of a dry hydrogel film (Fig. 3a). These pores reduce the ellipsometrically determined mean thickness, since they optically behave like the surrounding solution they are filled with. In the case of the acoustic measurement principle the liquid in the pores is moved together with the hydrogel film. They behave like part of the gel due to the very similar densities of hydrogel and liquid.

The systematic deviation between the absolute values $d_{\text {ellips }}$ and $d_{\text {sim }}$ is largely cancelled out for the relative values of the thickness change caused by shifts of the cleaner concentration (see row "Relative changes from 1 to 8 vol\% cleaner" in Table A3). This means that both measurement approaches are potentially suitable for assessing the swellability, which is related to the cross-linking density of the hydrogel film.

The indirectly measured storage moduli are more than 1 order of magnitude higher than the ones measured with the AFM. This outcome is in qualitative agreement with the expected stiffening of the polymer network at high frequencies (Lucklum et al., 1997). The value of $G_{\mathrm{AFM}}^{\prime}$ of the less swollen gel at $8 \mathrm{vol} \%$ cleaner concentration is peculiar for 
Table 1. Ellipsometry measurements of PVA/PAA films with different coating parameters.

\begin{tabular}{|c|c|c|c|c|c|c|c|c|c|c|c|}
\hline \multirow[t]{2}{*}{ No. } & \multirow{2}{*}{$\begin{array}{l}\text { No. of } \\
\text { TSRs }\end{array}$} & \multirow{2}{*}{$\begin{array}{c}c_{\mathrm{p}} \\
(\text { wt. } \%)\end{array}$} & \multirow{2}{*}{$\begin{array}{c}\omega \\
\left(\min ^{-1}\right)\end{array}$} & \multicolumn{4}{|c|}{$\eta(\mathrm{Pa} \cdot \mathrm{s})$ for different shear rates $s\left(\mathrm{~s}^{-1}\right)$} & \multirow[t]{2}{*}{$\bar{n}$} & \multirow{2}{*}{$\begin{array}{l}X(\bar{d}) \\
(\mathrm{nm})\end{array}$} & \multirow{2}{*}{$\begin{array}{l}s^{2}(\bar{d}) \\
(\mathrm{nm})\end{array}$} & \multirow{2}{*}{$\begin{array}{c}X\left[s^{2}(d)\right] \\
(\mathrm{nm})\end{array}$} \\
\hline & & & & 1 & 10 & 100 & 1000 & & & & \\
\hline 1 & 4 & 2.5 & 3900 & 0.0823 & 0.0778 & 0.0620 & 0.0404 & 1.529 & 159.3 & 1.7 & 6.9 \\
\hline 2 & 4 & 3.5 & 3750 & 0.2332 & 0.2028 & 0.1530 & 0.0949 & 1.548 & 323.4 & 2.6 & 5.8 \\
\hline 3 & 5 & 4.5 & 3350 & 0.4920 & 0.4253 & 0.3008 & 0.1773 & 1.563 & 525.5 & 17.0 & 7.9 \\
\hline 4 & 3 & 5.5 & 2500 & 1.3960 & 1.0842 & 0.7155 & 0.4119 & 1.565 & 1011.2 & 16.2 & 7.0 \\
\hline
\end{tabular}

$\mathrm{TSR}_{1}$, because it is smaller than the corresponding value of the highly swollen gel at $1 \mathrm{vol} \%$. This is contrary to the results for $\mathrm{TSR}_{2}$ and $\mathrm{TSR}_{3}$ and to the softening with increasing swelling degrees described in the literature (Arndt et al., 1999; Philippova and Khokhlov, 2012). The comparably high mean variance $\left(\mathrm{TSR}_{1}: 16.09 \mathrm{kPa}^{2} ; \mathrm{TSR}_{2}: 2.96 \mathrm{kPa}^{2}\right.$; $\mathrm{TSR}_{3}: 3.11 \mathrm{kPa}^{2}$ ) of the 225 single measurement points indicates a possible measurement deviation for $\mathrm{TSR}_{1}$. Therefore, the values $G_{\mathrm{AFM}}^{\prime}$ and $\Delta G_{\mathrm{AFM}}^{\prime}$ for $\mathrm{TSR}_{1}$ (values in brackets in Table A3) were excluded from the further evaluation of the results.

The remaining relative values $\Delta G_{\mathrm{AFM}}^{\prime}$ and $\Delta G_{\text {sim }}^{\prime}$ do not allow profound conclusions, since they differ significantly for $\mathrm{TSR}_{2}$, while they are in good agreement for $\mathrm{TSR}_{3}$.

The interrelation between storage moduli and swellability is in qualitative agreement with the expected behaviour. This means that the gel with the largest change in the thickness (high swellability, low cross-linking degree) has the lowest storage modulus and vice versa. However, the quantitative agreement is poor. The calculation of storage moduli $G_{\mathrm{cal}}^{\prime}$ using Eq. (3) yielded systematically much lower values than the measurements. This holds true for the application of Eq. (3) to the directly measured values as well as to the ones determined with the model-based approach (the results of the latter are not presented in Table A3). These results indicate that Eq. (1) is not valid for the high frequencies of the AFM and the QCM measurement.

In the aggregate, the results infer that both tested thickness measurement techniques are in principle applicable for the monitoring of quality-determining film properties. Future AFM-based thickness measurements could contribute to the understanding of the observed systematic deviation between the two techniques and help to develop rules for the mathematical correction of these deviations.

Further experiments and a broader database are necessary for the evaluation of the tested measurement techniques for the storage modulus. The approach based on the interrelation between the swelling degree and the storage modulus is - in the investigated form - not applicable for high measurement frequencies and is therefore not further pursued.

\section{Investigation and optimization of the manufacturing process}

\subsection{Spin-coating of homogenous polymer films}

Research objectives for the optimization of the spin-coating step are (i) the creation of uniform hydrogel films with a reproducible thickness within a batch and (ii) the development of a mathematical expression for the interrelations between the process parameters and the resulting thickness. To acquire the necessary experimental data, 16 TSRs were coated using different polymer concentrations and rotation speeds according to Table 1. Subsequently, the film thickness was measured with the VASE M-2000 ellipsometer in a dry state. In addition, the viscosity of the polymer solutions was measured at room temperature for different shear rates (Anton Paar Physica MCR 301; cone plate $\varnothing 50 \mathrm{~mm}$, angle $1^{\circ}$ ).

The following statistical parameters were calculated from the ellipsometry results.

$-\bar{d}$ : average thickness within one film

- $X(\bar{d})$ : average of $\bar{d}$ within the batch

$-s^{2}(\bar{d})$ : variance of the average film thickness within the batch

$-s^{2}(d)$ : thickness variance within one film

- $X\left[s^{2}(d)\right]:$ average of these variances within the batch

The values of these parameters in Table 1 illustrate the good homogeneity and reproducibility of the films. In agreement with qualitative simulation results of the electromechanical model, it can be concluded that such small deviations of the thickness are not the reason for the observed variance of the sensor sensitivity.

The second objective of the experimental investigation of the spin-coating step was the development of a relationship for pre-calculating the film thickness from the process parameters. Based on the works of Meyerhofer (1978) and Spangler et al. (1990), Eq. (6) was chosen as a general relation:

$d=C \frac{\left(\eta_{0} / P a \cdot s\right)^{a}}{\left(\omega / \min ^{-1}\right)^{y}}$, 


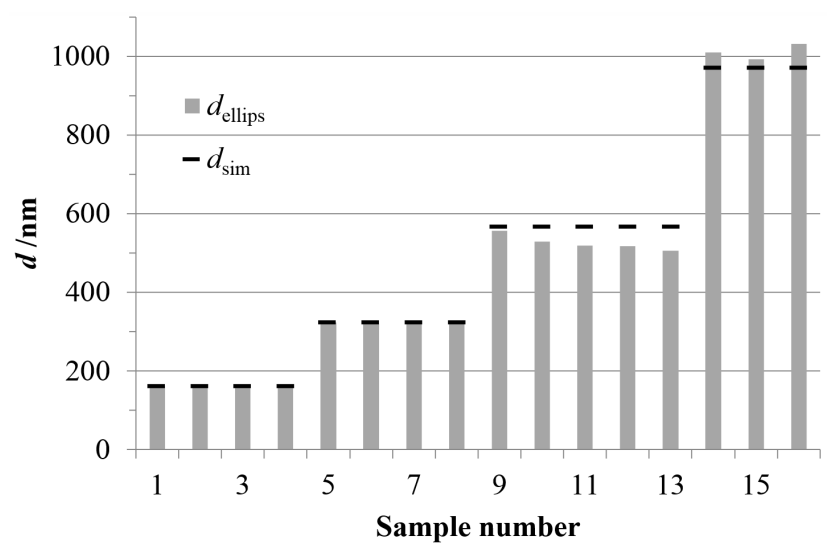

Figure 5. Measured and calculated film thickness.

where $C$ is a polymer-specific parameter, which depends on various physical polymer properties like the molecular weight.

Deviating from the aforementioned publications, the polymer concentration $c_{\mathrm{p}}$ is used as a parameter instead of the initial solution viscosity $\eta_{0}$, based on the approximation given in Eq. (7) (Spangler et al., 1990).

$\eta_{0}=\eta_{\text {solvent }}+\eta_{\text {solid }} c^{\gamma} \approx \eta_{\text {solid }} c_{\mathrm{p}}^{\gamma}$

for $\eta_{\text {solvent }} \ll \eta_{\text {solid }} c_{\mathrm{p}}^{\gamma}$.

The motivation for this approximation is the pronounced shear-thinning behaviour of the polymer solution (Table 1). Its viscosity decreases with increasing shear rates $s$. Since $s$ is unknown and not constant in the polymer solution during the spin-coating, it is ambiguous at which shear rate the value $\eta_{0}$ is to be measured. Therefore, $c_{\mathrm{p}}$ is used as a more feasible parameter.

The product $C \cdot \eta_{\text {solid }}^{a}$ was summarized in a single polymerspecific constant $k$. Writing the resulting exponent of $c_{\mathrm{p}}$ as $x=a \cdot \gamma$ leads to the quantity Eq. (8), which was used as a mathematical model for the spin-coating.

$d=k \frac{\left(c_{\mathrm{p}} / \mathrm{wt} . \%\right)^{x}}{\left(\omega / \min ^{-1}\right)^{y}}$

Factor $k$ must be determined for the PVA/PAA solution. Furthermore, different values had been reported for exponents $x$ and $y$ (Schubert and Dunkel, 2003; Jung et al., 2010). Consequently, all three parameters were determined from the experimental results by minimizing the least mean square error between the calculated and measured thicknesses. With the resulting values $k=1600 \mathrm{~nm}, x=1.99$ and $y=0.5$, the average relative error amounted to $3.8 \%$ (Fig. 5). Hence, Eq. (6) describes the interrelation between the process parameters and the hydrogel film properties for the spin-coating step sufficiently well. The excellent conformity with Meyerhofer's experimental results is remarkable $(x=2$ and $y=$ 0.5 ), although the shear-thinning phenomenon had not been taken into account for the underlying theoretical considerations.

\subsection{Thermal cross-linking}

A batch of 13 TSRs was spin-coated with equal parameters $\left(c_{\mathrm{p}}=2.5 \mathrm{wt} \% ; \omega=2500 \mathrm{~min}^{-1}\right)$ and evenly distributed in a laboratory oven (Binder VD 23) for the thermal cross-linking at $160{ }^{\circ} \mathrm{C}$ for $20 \mathrm{~min}$. The subsequently measured concentration curves showed large sensitivity differences of the sensors towards the selected proprietary industrial cleaner. These differences could be correlated with the position in the oven (Fig. 7). Considering the direct interrelation between Young's modulus (or shear modulus) and the cross-linking degree (Gerlach et al., 2009), this indicates a non-uniform cross-linking of the hydrogel layers in the oven.

The lack of an approved method for reliable measurements of the storage modulus (see Sect. 3) currently prevents quantitative studies of the interrelations between the cross-linking degree and the sensor sensitivity according to the methodology outlined in Fig. 2. However, the current state of research gives a reason for the hypothesis that the process parameters cross-linking temperature and time have an optimum with respect to the sensor sensitivity (for $d=$ const.). Arndt et al. (1999) found a strong non-linear interrelation between these parameters and the cross-linking degree of PVA/PAA. Higher temperatures or longer cross-linking times lead to more rigid (increased storage modulus, decreased loss modulus) and less swellable films. These mechanical properties affect the energy dissipation within the hydrogel film. The vibrational amplitude can be described as a function of the distance $z$ from the TSR surface (Mecea, 1994; Landau and Lifschitz, 1989):

$A(z)=A_{0} e^{-2 \omega \sqrt{\frac{\rho}{2 G^{\prime \prime}}} \cdot z}$,

where $A_{0}$ is the vibration amplitude at the TSR surface.

Equation (9) shows that the dissipation is lower in rigid films $\left(\downarrow G^{\prime \prime}\right)$. This means in the inverse that the penetration depth of the acoustic wave in soft rubbery films is limited by the higher dissipation. Based on these results, the following extreme cases can be anticipated for hydrogel-coated TSRs.

Very weakly cross-linked films become necessarily quite thick in liquid environments due to their high swelling degree, while the penetration depth of the acoustic wave is small. If this depth is smaller than the film thickness, the TSR cannot sense thickness changes, since the wave does not reach the gel surface. This means that the influence of $d_{\text {sim }}$ on $Z_{1}$ (Eq. 5) vanishes and only the concentration-dependent change in $G^{*}$ contributes to the sensor signal. The result is a reduced sensitivity. The other extreme case results in highly cross-linked films. Their very low swelling capability also limits the sensitivity of the sensor. Consequently, an optimum can be expected to exist somewhere between these two extremes. An empirical approach was pursued in order to 


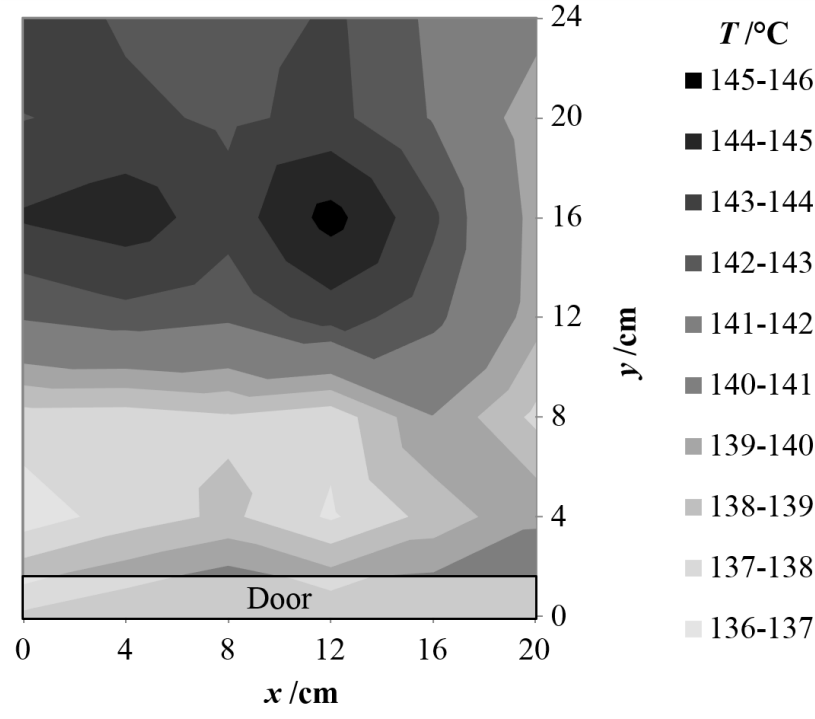

Figure 6. Temperature distribution in cross-linking oven after inserting the coated TSRs.

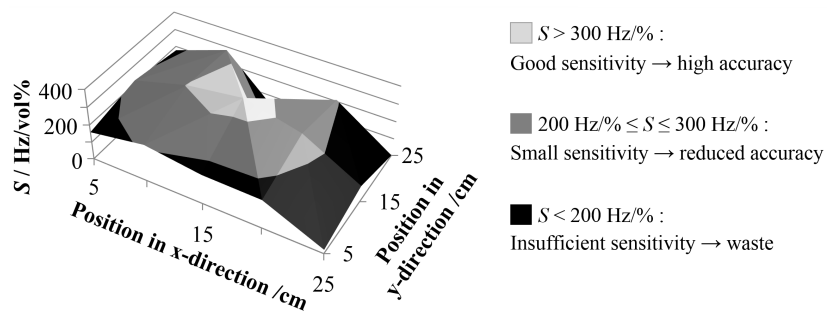

Figure 7. Effect of the inhomogeneous cross-linking temperature distribution in the oven on the resulting sensitivity and functionality of the manufactured sensor.

determine this optimum for the given sensor design without measurements of the mechanical film parameters.

The temperature field in the cross-linking oven was measured with a matrix of PT100 temperature sensors and an in-house developed signal processing device (max. measurement deviation in the range $20<T<180^{\circ} \mathrm{C}: \Delta T \leq 0.5 \mathrm{~K}$ ). Figure 6 shows the inhomogeneous temperature distribution with local differences of up to $10 \mathrm{~K}$ after inserting the coated TSRs into the preheated oven. The open door generates an air swirl, which cools the outer parts and causes a hot spot in the middle during the insertion time (about $30 \mathrm{~s}$ ). After closing the door, it takes about $4 \mathrm{~min}$ to restore the original temperature (with a maximum deviation $1 \mathrm{~K}$ ) in all areas of the oven. Afterwards, the temperature remains constant for the rest of the cross-linking step.

The similarities between the spatial distribution of temperature and sensitivity in Figs. 6 and 7 suggest the following explanation for the observed sensitivity deviations: the hot spot leads to a higher cross-linking degree of the hydrogel films in the middle of the oven. A consequence of that is

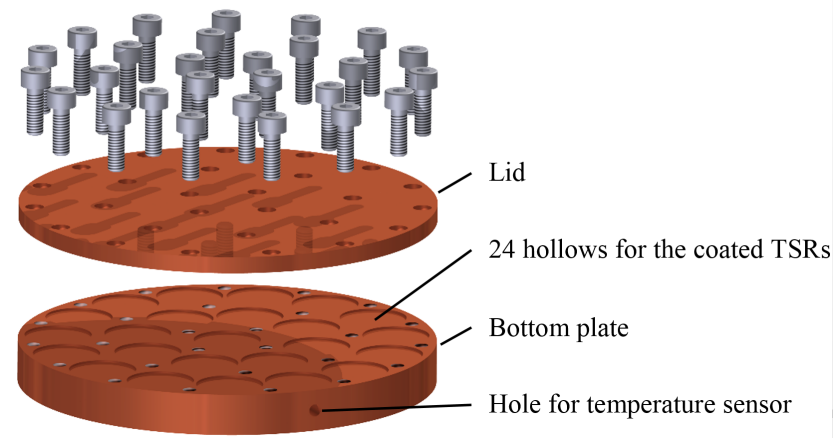

Figure 8. Cross-linking tool.

a higher Young's modulus of these hydrogels, which corresponds to a higher sensitivity, as the AFM measurements indicate. A possible reason why higher cross-linked - and thus less swellable - hydrogels exhibit a better sensitivity relates to the transducer principle: overly soft hydrogels do not sufficiently follow the shear oscillation of the TSR and therefore have less influence on the vibration behaviour of the system, even if they strongly swell.

\subsubsection{Development and investigation of a batch manufacturing tool}

A batch manufacturing tool for 24 TSRs made of massive copper was designed in order to unify and control the crosslinking temperature (Fig. 8). It reduces the spatial temperature differences to less than $0.3 \mathrm{~K}$ and has an integrated sensor for real-time temperature monitoring. One applicationdriven motivation for developing this tool was to provide defined and controllable thermal conditions in - compared to sophisticated thermal curing devices of the semiconductor industry - inexpensive lab ovens.

The temporal temperature profile in the tool was monitored, together with the spatial temperature distribution in the oven, during the cross-linking process step. Figure 9 shows the distribution of the temperature sensors on the shelf panel in the oven. In order to provide identical conditions for the heating and the cooling process, the tool was placed on an identical shelf panel outside of the oven for cooling down.

The measured profiles (Fig. 10) allow several conclusions. First of all, the steady-state temperature, the intensity of the cooling effect due to the open door as well as the time for recovering the initial temperature after closing the door vary with the position in the oven. For example, sensor 7, which was placed right behind the door, is generally cooler than the other sensors because of the heat loss through the door. This position is most distant to the heat sources and has therefore the longest recovery time. The opposite holds true for the sensors 5 and 6 , which are closest to the heat source (mantle heating) and do, therefore, hardly change their temperature. 


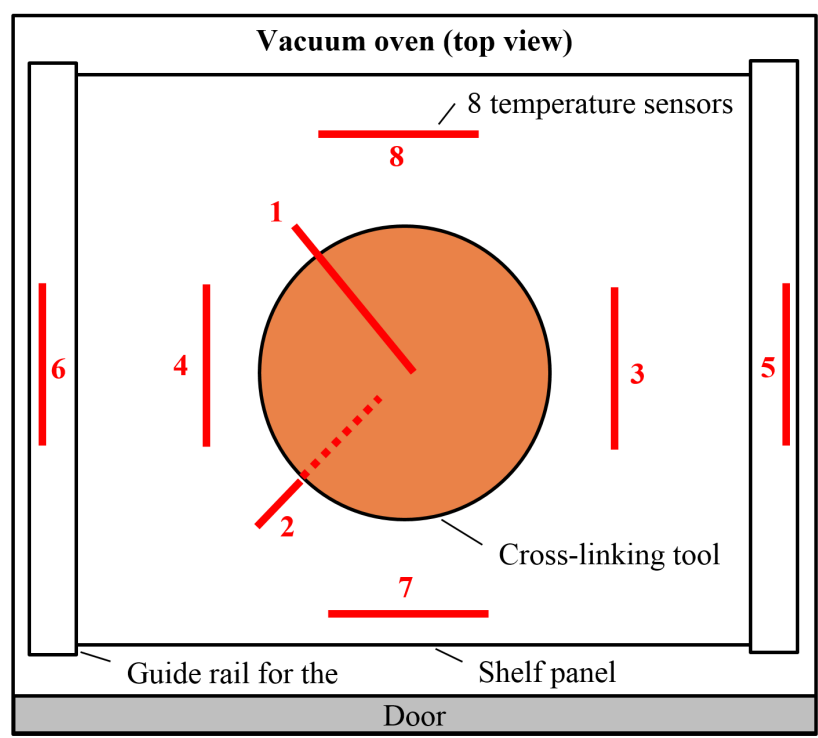

Figure 9. Sensor position in the cross-linking oven.

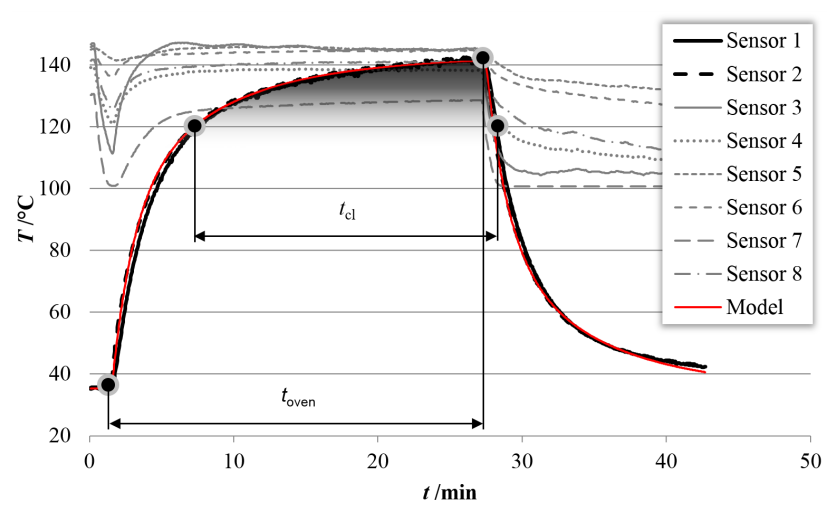

Figure 10. Temperature profile during the cross-linking process.

As a second outcome, Fig. 10 shows that the heat distribution within the cross-linking tool is sufficiently even. Sensor 1 was placed on the lid, while sensor 2 was placed in the hole in the bottom plate of the tool. The temperature of both sensors (bold curves) is almost equal.

The important manufacturing parameter is the crosslinking temperature profile $T_{\mathrm{cl}}(t)$. Arndt et al. (1999) have shown that the cross-linking rate reaches a significant level for temperatures above approximately $120^{\circ} \mathrm{C}$. It increases strongly non-linearly with rising temperatures up to about $160^{\circ} \mathrm{C}$. This means that the cross-linking time $t_{\mathrm{cl}}$ is the duration at temperatures above $120^{\circ} \mathrm{C}$. The resulting crosslinking degree $\iota$ and, therefore, the swellability and storage modulus of the gel, depend on the actual temperature profile within $t_{\mathrm{cl}}$. This area is grey-shaded in Fig. 10, where the colour gradient qualitatively indicates the non-linearly increasing cross-linking speed. The interrelation between the dwell time in the oven $t_{\text {oven }}$ (as the actual controllable pro-

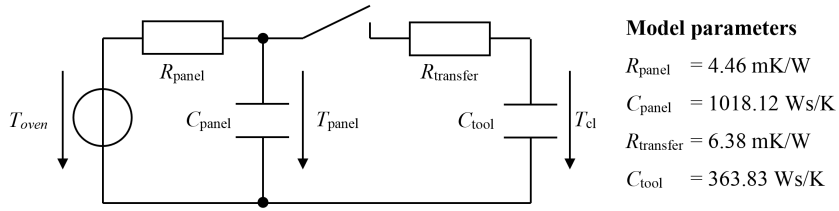

Figure 11. Equivalent thermal circuit.

cess parameter) and the manufacturing parameters $T_{\mathrm{cl}}(t)$ and $t_{\mathrm{cl}}$ is determined by the thermal time response of the system. Hence, this system behaviour must be sufficiently well known in order to enable the forward-control of the crosslinking process. This means in practice that values of the process parameters $t_{\text {oven }}$ and the temperature $T_{\text {oven }}$, at which the oven is pre-heated, can be pre-calculated for any given manufacturing parameters $t_{\mathrm{cl}}$ and $T_{\mathrm{cl}}(t)$.

The thermal system behaviour of the cross-linking tool in the oven was modelled using the method of electro-thermal analogies and thermal networks. Figure 11 shows the simplified equivalent circuit of the set-up. $C_{\text {tool }}$ is the heat capacitance of the copper tool. The tool is placed in the pre-heated oven on a thick (for better heat conductance) aluminium shelf panel with the heat capacitance $C_{\text {panel. }}$. Between the two elements is (due to surface roughness) a small air gap of a few micrometres that causes the transfer resistance $R_{\text {transfer. The }}$ heat conduction resistance of the shelf panel $R_{\text {panel }}$ limits the heat flow from the mantle of the oven to the cross-linking tool. The switch indicates the coupling of the pre-heated shelf panel and the cross-linking tool upon its insertion in the oven.

The system behaviour of the equivalent circuit given in Fig. 11 is described by

$T_{\mathrm{oven}}=A \frac{d^{2} T_{\mathrm{cl}}(t)}{\mathrm{d} t^{2}}+B \frac{\mathrm{d} T_{\mathrm{cl}}(t)}{\mathrm{d} t}+T_{\mathrm{cl}}(t)$

with $A=R_{\text {panel }} C_{\text {panel }} R_{\text {transfer }} C_{\text {tool }}$ and

$$
B=R_{\text {panel }} C_{\text {panel }}+R_{\text {panel }} C_{\mathrm{cl}}+R_{\text {transfer }} C_{\text {tool }} .
$$

The general solution of this differential equation is given by Eq. (11).

$T_{\mathrm{cl}}(t)=c_{1} e^{\frac{t\left(-\sqrt{B^{2}-4 A}-B\right)}{2 A}}+c_{2} e^{\frac{t\left(\sqrt{B^{2}-4 A}-B\right)}{2 A}}+T_{\text {oven }}$

The two constants $c_{1}$ and $c_{2}$ are calculated for the heating step using the boundary conditions $T_{\mathrm{cl}}(0)=T_{\mathrm{cl}, 0}$ and $\mathrm{d} T_{\mathrm{cl}}(0) / \mathrm{d} t=\left(T_{\text {oven }}-T_{\mathrm{cl}, 0}\right) /\left(C_{\text {tool }} \cdot R_{\text {transfer }}\right)$, with $T_{\mathrm{cl}, 0}$ being the initial temperature of the tool (e.g. room temperature). Denoting the two exponents in Eq. (11) as $t \cdot X$ and $t \cdot Y$, re- 


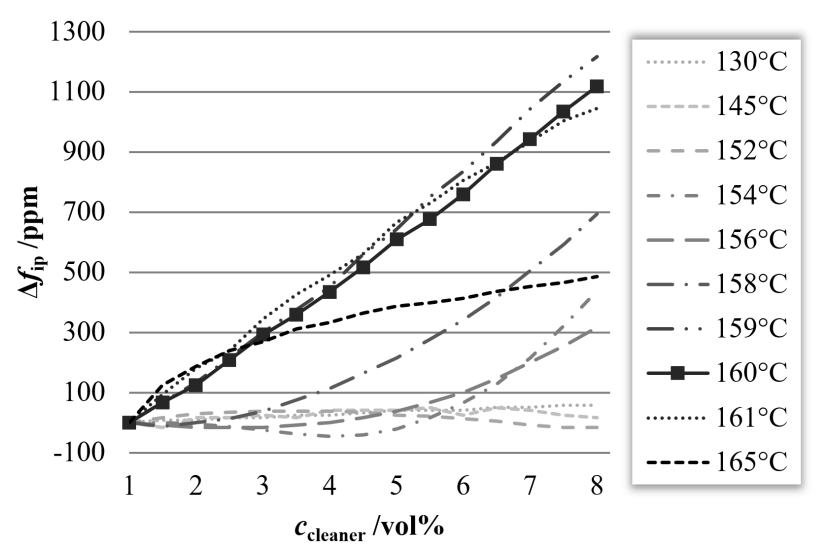

Figure 12. Normalized sensor sensitivity for different cross-linking temperatures at a given time $t_{\text {oven }}=25 \mathrm{~min}$ (see Table A4 for the corresponding $t_{\mathrm{cl}}$ values).

spectively, the analytical model is given by Eq. (12).

$$
\begin{aligned}
T_{\mathrm{cl}}(t)= & \left(T_{\text {oven }}-T_{\mathrm{cl}, 0}\right)\left[\frac{Y+1 /\left(C_{\text {tool }} \cdot R_{\text {transfer }}\right)}{X-Y} e^{t \cdot X}\right. \\
& \left.-\frac{X+1 /\left(C_{\text {tool }} \cdot R_{\text {transfer }}\right)}{X-Y} e^{t \cdot Y}\right]
\end{aligned}
$$

The constants for the cooling step (starting at $t_{1}$ with the temperature $\left.T_{\mathrm{cl}, 1}=T_{\mathrm{cl}}\left(t_{1}\right)\right)$ can be calculated the same way with the boundary conditions $T_{\mathrm{cl}}\left(t_{1}\right)=T_{\mathrm{cl}, 1}$ and $\mathrm{d} T_{\mathrm{cl}}\left(t_{1}\right) / \mathrm{d} t=-\left(T_{\text {oven }}-T_{\mathrm{cl}, 0}\right) /\left(C_{\text {tool }} \cdot R_{\text {transfer }}\right)$. It is assumed that the cool shelf plate outside of the oven, on which the hot cross-linking tool is put, has room temperature $\left(T_{\mathrm{cl}, 0}\right)$.

In order to apply Eq. (12) for controlling cross-linking processes, the values of the elements in the equivalent circuit need to be determined. The modelling of the cross-linking tool itself as concentrated element matches its real physical properties very closely. Its high heat conductivity eliminates any temperature differences within the copper body. Therefore, the value $C_{\mathrm{tool}}=363.83 \mathrm{Ws} \mathrm{K}^{-1}$ was calculated analytically from its mass $(945 \mathrm{~g})$ and the specific thermal heat capacity of copper $\left(385 \mathrm{Ws}(\mathrm{kg} \cdot \mathrm{K})^{-1}\right)$.

The heat capacitance and conduction resistance of the panel could not be calculated analytically because of the complex geometry of a special clamping mechanism inside and under the panel. Furthermore, the insertion of the cold cross-linking tool causes spatial temperature differences within the shelf plate. Hence, $C_{\text {panel }}$ and $R_{\text {panel }}$ can be regarded as virtually concentrated elements, which do not completely represent the real physical properties, but are suitable for describing the average heat conduction behaviour of the shelf panel. The value of $R_{\text {transfer }}$ cannot be pre-calculated analytically either, because it depends on the unknown microstructure of the contact surfaces. Hence, the values of $C_{\text {panel }}, R_{\text {panel }}$ and $R_{\text {transfer }}$ were determined by fitting (least squares method) the analytical model to the measured thermal time response of the cross-linking set-up (results denoted in Fig. 11). With these values, the heating and cooling steps were simulated (red graph in Fig. 10). They match the measured temperature profile very closely. This proves that the simplified model is suitable for the pre-calculation of crosslinking temperature profiles.

The developed cross-linking tool was used for the investigation of the temperature influence on the sensor sensitivity. A batch of 20 TSRs was coated with a PVA/PAA layer $\left(c_{\mathrm{p}}=2.5 \mathrm{wt} \%\right.$, spin-coater speed profile according to Table A1). The cross-linking was carried out with ten different temperatures $T_{\text {oven }}$. Two coated TSRs were placed in the cross-linking tool at each temperature. The process parameter $t_{\text {oven }}$ was kept constant to $20 \mathrm{~min}$. Equation (12) was used for calculating the resulting values for $t_{\mathrm{cl}}$ and $T_{\mathrm{cl} \text {,max }}$ (Table A4). Subsequent to the manufacturing, the sensitivity of the sensors was investigated by measuring the change in their inflection point frequency (Fig. 1) for the applicationrelevant concentration range of $1-8$ vol $\%$ industrial cleaner.

\subsubsection{Results}

Figure 12 shows the results of the investigation of the influence of the cross-linking temperature on the sensor sensitivity. The curves are the mean frequency change of the two samples for each temperature. The relative deviation between every two samples was within a maximum range of $12 \%$ for all samples. This indicates that the cross-linking tool significantly improved the reproducibility. The best sensitivity (about $1.6 \mathrm{kHz}$ vol\% ${ }^{-1}$ ) was achieved in the range of 159-161 ${ }^{\circ} \mathrm{C}$. Temperatures above $160^{\circ} \mathrm{C}$ lead to a decreased sensitivity. Therefore, the process parameters $T_{\text {oven }}=160^{\circ}$ $\mathrm{C}$ and $t_{\text {oven }}=20 \mathrm{~min}$ were chosen as a robust optimum. The corresponding parameters $t_{\mathrm{cl}}$ and $T_{\mathrm{cl}, \max }$ are printed in bold type in Table A4.

Another five sensors, which were manufactured as one batch with the cross-linking tool and the optimized parameters, exhibited sensitivities in the range of 1.3$1.6 \mathrm{kHz} \mathrm{vol} \%^{-1}$. This represents a yield of $100 \%$ for the selected industrial application.

\section{Conclusions}

The optimized manufacturing of hydrogel sensors requires specifications for measurable design parameters and knowledge about their interrelation to the controllable process parameters of the manufacturing technique. We have presented an acoustic sensor principle for industrial applications together with a basic, versatile coating technique for the manufacturing of thin hydrogel layers. The proposed process is easily scalable and very controllable because of the separation of the film formation and the cross-linking step. Due to these advantages, we suggest using it as a manufacturing standard and adapt the hydrogel synthesis, if necessary (and not vice versa). For example, Hirata et al. (2004) showed that 
a previously only chemically (in liquid state) cross-linkable hydrogel can be thermally cross-linked as well.

Several measurement techniques were tested for the quality-determining hydrogel film parameters storage modulus $G^{\prime}$ and thickness $d$. The thickness can in principle be measured with variable angle spectroscopic ellipsometry as well as with a model-based approach that uses the coated TSR itself for determining the film parameters. A systematic deviation between the thickness values obtained with these two techniques was observed. An in-depth study of this deviation with additional measurements using a third technique, such as AFM, is subject to future research.

The same holds true for the measurement of the storage modulus. Major deviations occurred between the values of $G^{\prime}$ measured with the model-based approach and the AFM, respectively. Further investigations are necessary in order to evaluate the obtained results. Furthermore, Eq. (3) seems to be not applicable for high frequencies. The swellingdependent changes in the storage moduli calculated from the thickness changes are 2 orders of magnitude smaller than the ones obtained by AFM and the model-based approach.

The investigation of the manufacturing process showed that the film thickness is sufficiently reproducible. Simulations using Eqs. (4) and (5) indicate that the remaining deviations within a batch do not cause the initially observed strong sensitivity variance (Fig. 1). Furthermore, an existing analytical model for the interrelation between the process parameters spin-coater speed $\omega$, polymer concentration $c_{\mathrm{p}}$ and resulting film thickness $d$ was successfully adapted to the manufacturing process of thin hydrogel films.
The strong influence of the cross-linking time $t_{\mathrm{cl}}$ and the temperature profile $T_{\mathrm{cl}}(t)$ on the sensor sensitivity (Fig. 12) suggests that the temperature deviations within the oven are the main reason for the initial sensitivity variance within a batch of sensors. A cross-linking tool was developed, which works as a heat spreader and reduces the spatial temperature deviations. Furthermore, an analytical model for the thermal system response of the cross-linking set-up was established and successfully tested. It interrelates the controllable process parameters $t_{\text {oven }}$ and $T_{\text {oven }}$ to the manufacturing parameters $t_{\mathrm{cl}}$ and $T_{\mathrm{cl}}(t)$. The application of the tool and the model for the optimization of the thermal cross-linking process step yielded a quintupled sensitivity and a significantly reduced variance.

The objective of providing optimal values and acceptable tolerance ranges for $d$ and $G^{\prime}$ could not be completely accomplished for the reason of lacking reliable measurement techniques. VASE, AFM and the model-based approach are promising candidates for this purpose. However, they could not be sufficiently validated within the scope of this paper to be regarded as proven techniques. Concepts for addressing this shortcoming in subsequent studies were pointed out. Finally, there is still a need for a second measuring technique to validate the values for $G^{\prime \prime}$ (respectively $\eta$ ), which will also be subject to future research. 
Appendix A: Additional data of the experimental part

Table A1. Speed profile for spin-coating.

\begin{tabular}{lc}
\hline Time (s) & Speed (rpm) \\
\hline 0 & 0 \\
5 & 250 \\
35 & 250 \\
60 & 2500 (or according to Table 1) \\
180 & 2500 (or according to Table 1) \\
195 & 500 \\
205 & 500 \\
210 & 0 \\
\hline
\end{tabular}

Table A2. Tested measurement techniques and their applicability for thin hydrogel layers.

\begin{tabular}{|c|c|c|c|}
\hline Measurand & Measurement technique & Instrument & Remarks on applicability \\
\hline $\bar{d}, n$ & $\begin{array}{l}\text { Variable angle spectroscopic } \\
\text { ellipsometry (VASE) }\end{array}$ & M-2000, J. A. Woollam Co. & Applicable \\
\hline$d(x y)$ & Interference measurement & $\begin{array}{l}\text { ETA-CSS-BID, } \\
\text { ETA-Optik GmbH }\end{array}$ & $\begin{array}{l}\text { Not applicable: reflectivity of the hydrogel } \\
\text { surface too low (compared to reflectivity of } \\
\text { the underlying gold electrode) }\end{array}$ \\
\hline $\bar{d}$ & $\mathrm{X}$-ray reflectometry (XRR) & $\begin{array}{l}\text { In-house development of the } \\
\text { Institute of Structural Physics } \\
\text { (TU Dresden) }\end{array}$ & $\begin{array}{l}\text { Not applicable: hydrogel layers are too } \\
\text { thick; no measurements in swollen state } \\
\text { possible }\end{array}$ \\
\hline$d(x y)$ & Confocal microscopy & NanoFOCUS $\mu$ Scan AF2000 & $\begin{array}{l}\text { Not applicable: overly high transmissivity } \\
\text { of the hydrogel prevents the detection of the } \\
\text { gel surface. }\end{array}$ \\
\hline $\begin{array}{l}E \\
d(x y)\end{array}$ & $\begin{array}{l}\text { Atomic force microscopy } \\
\text { (AFM) }\end{array}$ & $\begin{array}{l}\text { Nanowizard II, } \\
\text { JPK Instruments }\end{array}$ & $\begin{array}{l}\text { Applicable with limitations: } \\
G^{\prime} \text { is not measured directly, but calculated: } \\
G^{\prime}=\frac{E}{2(1+v)} \\
\text { measurement of } d(x y) \text { requires scratching } \\
\text { the gel layer }\end{array}$ \\
\hline
\end{tabular}


Table A3. Parameter determination of the model-based indirect measurement approach.

\begin{tabular}{|c|c|c|c|c|c|}
\hline & Parameter & $\mathrm{TSR}_{1}$ & $\mathrm{TSR}_{2}$ & $\mathrm{TSR}_{3}$ & Determination of parameter value \\
\hline \multirow{3}{*}{ TSR } & $\begin{array}{l}K \\
v_{\mathrm{q}}\left(\mathrm{m} \mathrm{s}^{-1}\right) \\
Z_{\mathrm{q}}\left(10^{6} \mathrm{~kg}\left(\mathrm{~m}^{2} \mathrm{~s}\right)^{-1}\right)\end{array}$ & & $\begin{array}{c}0.0893 \\
3321.2 \\
8.795 \\
\end{array}$ & & $\begin{array}{l}\text { Material constants from the literature } \\
\text { (Bruenig, 2011) }\end{array}$ \\
\hline & $\begin{array}{l}d_{\mathrm{q}}(\mu \mathrm{m}) \\
C_{\mathrm{p}}(\mathrm{pF})\end{array}$ & $\begin{array}{r}165.31 \\
6.6\end{array}$ & $\begin{array}{r}165.17 \\
6.52\end{array}$ & $\begin{array}{r}165.51 \\
6.22\end{array}$ & $\begin{array}{l}\text { Extracted from model by matching } \\
\text { the measured and simulated spectrum of the } \\
\text { unloaded TSRs (prior to hydrogel coating) }\end{array}$ \\
\hline & $C_{\mathrm{s}}(\mathrm{pF})$ & 7.35 & 6.21 & 7.97 & $\begin{array}{l}\text { Extracted from model (spectrum of loaded TSR } \\
\text { outside of the resonance range) }\end{array}$ \\
\hline \multirow[t]{2}{*}{ Liquid half space } & $\begin{array}{l}\rho_{w, 1 \mathrm{vol} \%}\left(\mathrm{~g} \mathrm{~cm}^{-3}\right) \\
\rho_{w, 8 \mathrm{vol} \%}\left(\mathrm{~g} \mathrm{~cm}^{-3}\right)\end{array}$ & & $\begin{array}{l}1.015 \\
1.065\end{array}$ & & $\begin{array}{l}\text { Measured with hydrometer } \\
\text { (uncertainty: } \pm 0.005 \mathrm{~g} \mathrm{~cm}^{-3} \text { ) }\end{array}$ \\
\hline & $\begin{array}{l}\eta_{w, 1 \mathrm{vol} \%}\left(\mathrm{mPa} \mathrm{s}^{-1}\right) \\
\eta_{w, 8 \mathrm{vol} \%}\left(\mathrm{mPa} \mathrm{s}^{-1}\right)\end{array}$ & & $\begin{array}{l}1.8 \\
1.9\end{array}$ & & $\begin{array}{l}\text { Extracted from model (uncoated } \\
\text { TSR with liquid half space as load) }\end{array}$ \\
\hline Dry film & $\begin{array}{l}d_{\text {ellips }}(\mathrm{nm}) \\
n(\lambda=632.8 \mathrm{~nm})\end{array}$ & $\begin{array}{l}208.3 \\
1.514 \\
\end{array}$ & $\begin{array}{l}231.4 \\
1.515\end{array}$ & $\begin{array}{l}137.3 \\
1.489 \\
\end{array}$ & Measured with VASE \\
\hline \multirow{5}{*}{$\begin{array}{l}\text { Hydrogel film in aqueous } \\
\text { solution with a cleaner con- } \\
\text { centration of } 1 \text { vol } \%\end{array}$} & $\rho\left(\mathrm{g} \mathrm{cm}^{-3}\right)$ & 1.11 & 1.12 & 1.12 & Calculated from thickness change \\
\hline & $\begin{array}{l}d_{\text {ellips }}(\mathrm{nm}) \\
n(\lambda=632.8 \mathrm{~nm})\end{array}$ & $\begin{array}{l}690.4 \\
1.391\end{array}$ & $\begin{array}{l}701.9 \\
1.398\end{array}$ & $\begin{array}{l}401.7 \\
1.389\end{array}$ & $\begin{array}{l}\text { Measured in situ with spectroscopic } \\
\text { ellipsometry at an angle of incident of } 70^{\circ}\end{array}$ \\
\hline & $d_{\text {sim }}(\mathrm{nm})$ & 850 & 750 & 550 & $\begin{array}{l}\text { Extracted from model (PVA/PAA-coated TSR } \\
\text { with liquid half space) }\end{array}$ \\
\hline & $G_{\text {AFM }}^{\prime}(\mathrm{kPa})$ & 27 & 33.7 & 33.3 & $\begin{array}{l}\text { Measured in situ with AFM (average of } \\
\text { altogether } 225 \text { measurement points in three } \\
\text { areas of } 100 \mu \mathrm{m} \times 100 \mu \mathrm{m} \text { each) }\end{array}$ \\
\hline & $\begin{array}{l}G_{\text {sim }}^{\prime}(\mathrm{kPa}) \\
\eta_{\mathrm{sim}}\left(\mathrm{mPa} \mathrm{s}^{-1}\right)\end{array}$ & $\begin{array}{r}600 \\
59\end{array}$ & $\begin{array}{r}1300 \\
57\end{array}$ & $\begin{array}{r}700 \\
37\end{array}$ & $\begin{array}{l}\text { Extracted from model (PVA/PAA-coated TSR } \\
\text { with liquid half space) }\end{array}$ \\
\hline \multirow[t]{3}{*}{$\begin{array}{l}\text { Hydrogel film in aqueous } \\
\text { solution with a cleaner con- } \\
\text { centration of } 8 \text { vol } \%\end{array}$} & $\begin{array}{l}\rho\left(\mathrm{g} \mathrm{cm}^{-3}\right) \\
d_{\text {ellips }}(\mathrm{nm}) \\
n(\lambda=632.8 \mathrm{~nm}) \\
d_{\text {sim }}(\mathrm{nm}) \\
G^{\prime} \text { AFM }(\mathrm{kPa}) \\
G_{\text {sim }}^{\prime}(\mathrm{kPa}) \\
\end{array}$ & $\begin{array}{r}1.12 \\
606.5 \\
1.4 \\
720 \\
(19) \\
1900\end{array}$ & $\begin{array}{r}1.12 \\
681.1 \\
1.408 \\
710 \\
211 \\
4500\end{array}$ & $\begin{array}{r}1.14 \\
355.8 \\
1.401 \\
480 \\
198 \\
4200\end{array}$ & $\begin{array}{l}\text { Same as parameter determination } \\
\text { for } 1 \mathrm{vol} \%\end{array}$ \\
\hline & $G_{\mathrm{cal}}^{\prime}(\mathrm{kPa})$ & 28.2 & 34 & 34.7 & Calculated using Eq. (3) \\
\hline & $\eta_{\mathrm{sim}}\left(\mathrm{mPa} \mathrm{s}^{-1}\right)$ & 64 & 65 & 40 & Same as parameter determination for 1 vol $\%$ \\
\hline $\begin{array}{l}\text { Relative changes from } 1 \text { to } \\
8 \text { vol\% cleaner }\end{array}$ & $\begin{array}{l}\Delta d_{\text {ellips }}(\%) \\
\Delta d_{\text {sim }}(\%) \\
\Delta G^{\prime} \mathrm{AFM}(\%) \\
\Delta G_{\text {sim }}^{\prime}(\%)\end{array}$ & $\begin{array}{r}12.2 \\
15.5 \\
(-29.6) \\
216.7 \\
\end{array}$ & $\begin{array}{r}3 \\
5 \\
526.1 \\
246.2\end{array}$ & $\begin{array}{r}11.4 \\
12.7 \\
495.6 \\
500\end{array}$ & $\begin{array}{l}\text { Calculated from absolute values measured at } 1 \\
\text { and } 8 \text { vol } \% \text { cleaner concentration }\end{array}$ \\
\hline Sensor sensitivity & $S\left(\mathrm{~Hz} \mathrm{vol}^{-1}\right)$ & 245 & 268 & 136 & $\begin{array}{l}\text { Average concentration-dependent shift of the } \\
\text { inflection point frequency between } 1 \text { and } \\
8 \text { vol\% cleaner concentration (calculated from } \\
\text { spectra measured with Agilent R3765CG VNA) }\end{array}$ \\
\hline
\end{tabular}


Table A4. Pre-calculated cross-linking parameters (for $T_{\mathrm{cl}, 0}=$ $22^{\circ} \mathrm{C}$ and $t_{\text {oven }}=25 \mathrm{~min}$ ). The bold font indicates the optimal parameter set.

\begin{tabular}{lrr}
\hline$T_{\text {oven }}\left({ }^{\circ} \mathrm{C}\right)$ & $t_{\mathrm{cl}}(\min )$ & $T_{\mathrm{cl}, \max }\left({ }^{\circ} \mathrm{C}\right)$ \\
\hline 130 & 14.20 & 128.67 \\
145 & 19.63 & 143.48 \\
152 & 20.85 & 150.40 \\
154 & 21.11 & 152.37 \\
156 & 21.35 & 154.35 \\
158 & 21.61 & 156.32 \\
159 & 21.70 & 157.31 \\
$\mathbf{1 6 0}$ & $\mathbf{2 1 . 8 1}$ & $\mathbf{1 5 8 . 3 0}$ \\
161 & 21.93 & 159.28 \\
165 & 21.97 & 163.24 \\
\hline
\end{tabular}


Acknowledgements. This research was funded by a PhD scholarship of the German National Academic Foundation. Previous financial support of R\&D project Prozessmesstechnik zur Badueberwachung in der Oberflaechentechnik mittels Hydrogelsensoren by the EU (ERDF, European Regional Development Funds) and the Free State of Saxony is gratefully acknowledged. The authors also thank the former project partner SITA Messtechnik GmbH for the supplied material and S. Abril-Guevara, A. Gehre, L. Guenther, J. Nowak and Y. Wang for supporting the experimental section with measurements and test rigs. Furthermore, the authors are indebted to Jens Friedrichs (Max Bergmann Center) for the AFM measurements and R. Schulze (Leibniz Institute of Polymer Research Dresden) for the VASE measurements.

Edited by: A. Schütze

Reviewed by: two anonymous referees

\section{References}

Arndt, K.-F., Richter, A., Ludwig, S., Zimmermann, J., Kressler, J., Kuckling, D., and Adler, H. J.: Poly(vinyl alcohol)/poly(acrylic acid) hydrogels: FT-IR spectroscopic characterization of crosslinking reaction and work at transition point, Acta Polym., 50, 383-390, 1999.

Arndt, K.-F., Krahl, F., Richter, S., and Steiner, G.: SwellingRelated Processes in Hydrogels, in: Hydrogel Sensors and Actuators, edited by: Gerlach, G. and Arndt, K.-F., Vol. 6, Springer Science \& Business Media, Heidelberg, Germany, 69-136, 2009.

Bashir, R., Hilt, J. Z., Elibol, O., Gupta, A., and Peppas, N. A.: Micromechanical cantilever as an ultrasensitive $\mathrm{pH}$ microsensor, Appl. Phys. Lett., 81, 3091-3093, 2002.

Bittrich, E., Uhlmann, P., Eichhorn, K.-J., Hinrichs, K., Aulich, D., and Furchner, A.: Polymer Brushes, Hydrogels, Polyelectrolyte multilayers: Stimuli responsivity and control of protein adsorption, in: Ellipsometry of Organic Surfaces and Thin Films, edited by: Hinrichs, K. and Eichhorn, K.-J., Springer-Verlag, BerlinHeidelberg, 79-105, 2014.

Bruenig, R.: Modellierung von akustischen Dickenscherschwingern im Frequenzbereich, Dr. Hut, Munich, Germany, 2011.

Buller, J., Laschewsky, A., and Wischerhoff, E.: Photoreactive oligoethylene glycol polymers-versatile compounds for surface modification by thin hydrogel films, Soft Matter, 9, 929-937, 2013.

Domke, J. and Radmacher, M.: Measuring the elastic properties of thin polymer films with the atomic force microscope, Langmuir, 14, 3320-3325, 1998.

Gerlach, G., Guenther, M., Sorber, J., Suchaneck, G., Arndt, K.-F., and Richter, A.: Chemical and $\mathrm{pH}$ sensors based on the swelling behavior of hydrogels, Sensor Actuat. B-Chem., 111, 555-561, 2005

Gesang, T., Fanter, D., Hoeper, R., Possart, W., and Hennemann, O. D.: Comparative film thickness determination by atomic force microscopy and ellipsometry for ultrathin polymer films, Surf. Interface Anal., 797-808, 1995.

Hegewald, J., Schmidt, T., Gohs, U., Günther, M., Reichelt, R., Stiller, B., and Arndt, K.-F.: Electron beam irradiation of poly (vinyl methyl ether) films: 1. Synthesis and film topography, Langmuir, 21, 6073-6080, 2005.
Hirata, I., Okazaki, M., and Iwata, H.: Simple method for preparation of ultra-thin poly(n-isopropylacrylamide) hydrogel layers and characterization of their thermo-responsive properties, Polymer, 45, 5569-5578, doi:10.1016/j.polymer.2004.06.015, 2004.

Jung, J. Y., Kang, Y. T., and Koo, J.: Development of a new simulation model of spin coating process and its application to optimize the $450 \mathrm{~mm}$ wafer coating process, Int. J. Heat Mass Tran., 53 , 1712-1717, 2010.

Landau, L. and Lifschitz, E.: Mécanique des fluides, Éditions Mir, Paris, vol. 6., 752 pp., 1989.

Lucklum, R., Behling, C., Cernosek, R. W., and Martin, S. J.: Determination of complex shear modulus with thickness shear mode resonators, J. Appl. Phys., 30, 346-356, 1997.

Markert, C. D., Guo, X., Skardal, A., Wang, Z., Bharadwaj, S., Zhang, Y., Bonin, K., and Guthold, M.: Characterizing the micro-scale elastic modulus of hydrogels for use in regenerative medicine, J. Mech. Behav. Biomed., 27, 115-127, 2013.

Mason, W. P.: Piezoelectric crystals and their application to ultrasonics, D. van Nostrand, van Nostrand, USA, 1950.

Mecea, V. M.: Loaded vibrating quartz sensors, Sensor Actuat. APhys., 40, 1-27, 1994.

Meyerhofer, D.: Characteristics of resist films produced by spinning, J. Appl. Phys., 49, 3993-3997, doi:10.1063/1.325357, 1978.

Ogieglo, W., Wormeester, H., Eichhorn, K.-J., Wessling, M., and Benes, N. E.: In situ ellipsometry studies of thin swollen polymer films, a review, Prog. Polym. Sci., 42, 42-48, 2015.

Philippova, O. E. and Khokhlov, A. R.: Polymer Gels, in: Polymer Science: A Comprehensive Reference, edited by: Matyjaszewski K. and Moeller, M., Elsevier, Amsterdam, 339-366, 2012.

Richter, A., Bund, A., Keller, M., and Arndt, K.-F.: Characterization of a microgravimetric sensor based on $\mathrm{pH}$ sensitive hydrogels, Sensor Actuat. B-Chem., 99, 579-585, 2004.

Schubert, D. W. and Dunkel, T.: Spin coating from a molecular point of view: its concentration regimes, influence of molar mass and distribution, Mater. Res. Innov., 7, 314-321, 2003.

Spangler, L. L., Torkelson, J. M., and Royal, J. S.: Influence of Solvent and Molecular Weight in Thickness and Surface Topography of Spin-Coated Polymer Films, Polym. Eng. Sci., 30, 644653, 1990.

Tokarev, I. and Minko, S.: Stimuli-responsive hydrogel thin films, Soft Matter, 5, 511-524, doi:10.1039/B813827C, 2009.

Trinh, Q. T., Gerlach, G., Sorber, J., and Arndt, K.-F.: Hydrogelbased piezoresistive $\mathrm{pH}$ sensors: design, simulation and output characteristics, Sensor Actuat. B-Chem., 117, 17-26, 2006.

Weihnacht, M., Bruenig, R., and Schmidt, H.: More accurate simulation of quartz crystal microbalance (QCM) response to viscoelastic loading, IEEE Ultrasonics Symposium, New York, NY, 28-31 October 2007, 377-380, 2007.

Williams, M. L., Landel, R. F., and Ferry, J. D.: The temperature dependence of relaxation mechanisms in amorphous polymers and other glass forming liquids, J. Am. Chem. Soc., 77, 37013707, 1955.

Windisch, M. and Junghans, T.: Hydrogel Sensors for Process Monitoring, Adv. Sci. Tech., 77, 71-76, doi:10.4028/www.scientific.net/AST.77.71, 2013.

Windisch, M. and Junghans, T.: Innovative Hydrogel Sensor Solution for Process Monitoring, Sci-eConf 2014 conference proceedings, 2014. 